\title{
Morbidity and mortality on combination versus monotherapy: a posthoc analysis of the Systolic Hypertension in Europe trial
}

\author{
Lutgarde Thijs $^{\mathrm{a}}$, Tom Richart ${ }^{\mathrm{a}, \mathrm{b}}$, Peter W. de Leeuw ${ }^{\mathrm{c}, \mathrm{d}}$, Tatiana Kuznetsova ${ }^{\mathrm{a}}$, \\ Tomasz Grodzicki ${ }^{\mathrm{e}}$, Kalina Kawecka-Jaszcz ${ }^{\dagger}$, Eoin O'Brien ${ }^{g}$, Josep Redón ${ }^{\text {h}}$, \\ Willem H. Birkenhäger ${ }^{i}$ Robert Fagard ${ }^{a}$ and Jan A. Staessen ${ }^{a, b}$
}

\begin{abstract}
Background The current literature supports the immediate use of combinations of antihypertensive drugs in terms of ease of use and adherence, but the key issue whether combination therapy is more effective than monotherapy in the prevention of cardiovascular complications remains unproven.
\end{abstract}

Methods We analysed the double-blind (median follow-up 2.0 years) and open follow-up (6.0 years) phases of the Systolic Hypertension in Europe trial. Patients were 60 years or more with an entry systolic/diastolic blood pressure (BP) of $160-219 /$ less than $95 \mathrm{mmHg}$. Antihypertensive treatment started immediately after randomization in the active-treatment group, but only after completion of the double-blind trial in control patients. Treatment consisted of nitrendipine $(10-40 \mathrm{mg} / \mathrm{day})$ with the possible addition of enalapril (5-20 mg/day). We adjusted our analyses for sex, age, history of cardiovascular complications, baseline systolic BP and previous antihypertensive treatment.

Results During the double-blind trial, adding enalapril to nitrendipine $(n=515)$, compared with the equivalent combination of placebos $(n=559)$, decreased systolic BP by a further $9.5 \mathrm{mmHg}$ and reduced all cardiovascular events by $51 \%(P=0.0035)$ and heart failure by $66 \%$ $(P=0.032)$, with similar trends for stroke $(-51 \% ; P=0.066)$ and cardiac events $(-44 \% ; P=0.075)$. Over the whole duration of follow-up, combination therapy $(n=871)$, compared with nitrendipine monotherapy $(n=1552)$, decreased systolic BP by $3.1 \mathrm{mmHg}$ and reduced total mortality $(-32 \% ; P=0.023)$, with similar trends for all

\section{Introduction}

Hypertension remains the leading cause of cardiovascular morbidity and mortality worldwide [1]. Unfortunately, the rule of halves still applies even in affluent European countries [2]. About one-third of the population is hypertensive. Of those who are hypertensive, only $50 \%$ are on antihypertensive medications. Of those on blood pressure (BP) lowering drugs, only $50 \%$ have their BP controlled [2].

The guidelines published by the European Societies of Hypertension and Cardiology (ESH/ESC) [3] and the Joint National Committee on Prevention, Detection, cardiovascular events $(-23 \% ; P=0.081)$ and stroke $(-42 \% ; P=0.054)$.

Conclusion Despite the limitations of a posthoc analysis, but congruent with the stronger BP reduction, our results suggest that combination therapy with nitrendipine plus enalapril might improve outcome over and beyond the benefits seen with nitrendipine monotherapy. $J$ Hypertens 28:865-874 (c) 2010 Wolters Kluwer Health | Lippincott Williams \& Wilkins.

Journal of Hypertension 2010, 28:865-874

Keywords: antihypertensive treatment, blood pressure, enalapril, isolated systolic hypertension, nitrendipine

Abbreviations: ACE, angiotensin-converting enzyme; BP, blood pressure; $\mathrm{Cl}$, confidence interval; $\mathrm{PI}$, percentile interval

${ }^{a}$ The Studies Coordinating Centre, Division of Hypertension and Cardiovascula Rehabilitation, Department of Cardiovascular Diseases, University of Leuven, Leuven, Belgium, ${ }^{b}$ Department of Epidemiology, ${ }^{\circ}$ Cardiovascular Research Institute, ${ }^{d}$ Department of Internal Medicine, Maastricht University, Maastricht, The Netherlands, e'Department of Internal Medicine and Gerontology, ${ }^{f}$ First Department of Cardiology and Hypertension, Jagiellonian University Medical College, Kraków, Poland, ${ }^{9}$ Conway Institute of Biomolecular and Biomedical Research, University College Dublin, Dublin, Ireland, ${ }^{n}$ Fundacion de Investigacion Hospital Clinico Valencia, University of Valencia, Valencia, Spain and 'Erasmus University, Rotterdam, The Netherlands

Correspondence to Jan A. Staessen, MD, PhD, FESC, FAHA, Studies Coordinating Centre, Laboratory of Hypertension, University of Leuven, Campus Sint Rafaël, Kapucijnenvoer 35, Block d Level 00, B-3000 Leuven, Belgium Tel: +32 16347104 ; fax: +32 16347106 ;

e-mail: jan.staessen@med.kuleuven.be and ja.staessen@epid.unimaas.n

Received 23 September 2009 Revised 1 December 2009 Accepted 4 December 2009

Evaluation, and Treatment of High Blood Pressure (JNC7) [4] recommend the initiation of antihypertensive treatment with combination therapy as an alternative to titrating, rotating and sequentially combining BP-lowering drugs of different classes. According to the ESH/ ESC guideline [3], combination therapy has several advantages. Using the combination of two drugs at a low dose might avoid side-effects [3]. Second, adherence decreases with the pill burden [5]. Moreover, combination therapy gets round the time-consuming search for an effective monotherapy, so that BP targets can be reached faster [3]. Although the current literature supports the aforementioned contentions, the key issue

DOI:10.1097/HJH.0b013e32833627c9 
whether combination therapy is more effective than monotherapy in the prevention of the cardiovascular complications associated with hypertension remains unproven. We, therefore, did a retrospective analysis of the database of the Systolic Hypertension in Europe trial (Syst-Eur) [6-8].

\section{Methods}

\section{Study design}

The protocol of the Syst-Eur trial has been described in detail elsewhere [6-8]. In summary, eligible patients had to be at least 60 years old. They had a sitting systolic BP between 160 and $219 \mathrm{mmHg}$, with diastolic BP below $95 \mathrm{mmHg}$ and a standing systolic BP of at least $140 \mathrm{mmHg}$. The entry BP was the mean of six sphygmomanometric readings with the patients seated, that is, two readings at each of three run-in visits on single-blind placebo. The Ethics Committees of the University of Leuven and the participating centres approved the protocol of the Syst-Eur trial. The Helsinki declaration for investigation in human participants served as the standard for the implementation of the trial. All participants in the 198 centres gave informed consent.

After stratification by centre, sex and previous cardiovascular complications, patients were randomized to doubleblind treatment with either active medication $(n=2398)$ or matching placebo $(n=2297)$. The study medications were stepwise titrated and combined to reduce sitting systolic BP by $20 \mathrm{mmHg}$ or more to less than $150 \mathrm{mmHg}$. Active treatment was initiated with nitrendipine (firstline medication, $10-40 \mathrm{mg}$ per day). If necessary to reach the systolic target BP, the calcium channel blocker was combined with or replaced by enalapril (second-line medication, 5-20 mg per day), hydrochlorothiazide (third-line medication, $12.5-25 \mathrm{mg}$ per day) or both. In the control group, placebos matching the first-line, second-line and third-line active drugs were used similarly. All active medications and matching placebos were administered as single tablets.

When the double-blind trial was stopped on 14 February 1997 [7], after a median follow-up of 2.0 years, the patients of the control group were switched to active antihypertensive therapy with the same study medications as used before in the active-treatment group, whereas the patients initially allocated active treatment continued active treatment [9]. In treatment-resistant patients, the open-label study medication could be associated with, or replaced by, any other antihypertensive drug. The extended follow-up ended on 31 December 2001 [9].

During the double-blind trial [6,7] and during the first year of the open-label study [9], clinic visits were scheduled every 3 months. From the second year of the openlabel follow-up onwards, reports were due every 6 months
[9]. At each visit, $\mathrm{BP}$ was measured twice in the sitting position and the two $\mathrm{BP}$ readings were averaged for analysis. For patients who withdrew from the study or who could not be followed up as planned, investigators collected information on vital status and incidence of endpoints at annual intervals. The Endpoint Committee, whose members were unaware of the random treatment allocation, reviewed the outcomes defined in the study protocols.

New-onset diabetes mellitus was the use of antidiabetic drugs, a fasting blood glucose concentration of at least $7.0 \mathrm{mmol} / \mathrm{l}$, a random blood glucose concentration of at least $11.1 \mathrm{mmol} / \mathrm{l}$ or diabetes documented in practice or hospital records [10].

\section{Statistical analysis}

For database management and statistical analysis, we used SAS version 9.2 (SAS Institute, Cary, North Carolina, USA). Comparison of means, medians and proportions relied on the standard normal z-test, MannWhitney test and the $\chi^{2}$-statistic, respectively. Statistical significance was a $P$ value of 0.05 or less on two-sided tests. The BP-lowering effect of enalapril in patients uncontrolled on nitrendipine was calculated by subtracting the BP after adding the second-line medication to the first-line study drug from the BP most recently preceding the initiation of enalapril treatment. Net between-group $\mathrm{BP}$ differences were calculated by subtracting the mean change during active treatment from the corresponding mean change in the control group.

The impact of combination therapy with nitrendipine and enalapril on outcome was assessed using two different approaches. The first approach only included data collected during the double-blind trial. The outcomes in patients randomized to active treatment and treated with nitrendipine plus enalapril were compared with those on the placebo's equivalent of this combination [8]. The second approach considered information collected during both the double-blind [6,7] and open-label [9] phases of the study. Patients on active treatment with nitrendipine and enalapril were compared with patients remaining on nitrendipine monotherapy for the duration of the study. In the patients initially randomized to active treatment, baseline was set at the date of randomization, whereas in patients initially randomized to placebo, baseline was defined as the date of entry into the open label followup study.

All outcome analyses were performed according to the intention-to-treat principle. For clinical signs, symptoms and complaints, a per-protocol approach was applied. Unadjusted and adjusted between-group comparisons of disease outcomes relied on the log-rank test and Cox regression analysis, respectively. In Cox regression, we adjusted for sex, age, baseline systolic BP, previous 
cardiovascular complications and the phase of the study (open-label vs. double-blind phase, if applicable).

\section{Results}

\section{Baseline characteristics}

Of the 2398 patients randomized to active treatment, 1327 remained on monotherapy with nitrendipine for the whole duration of the double-blind trial, 515 progressed to combination therapy with nitrendipine and enalapril, 405 received hydrochlorothiazide and the remaining 151 were either on monotherapy with enalapril or were treated with unknown drugs (Fig. 1). The corresponding numbers in the 2297 patients initially randomized to placebo were 859, 559, 782 and 97, respectively. Figure 2 shows the proportion of patients progressing during the double-blind trial to combination therapy with enalapril.

Age at randomization averaged $70.2 \pm 6.7$ years (Table 1 ). Patients progressing to the second-line medication, compared with those remaining on monotherapy with the first-line medication, were more frequently treated with antihypertensive drugs before randomization (48.6 vs.
$43.0 \% ; P=0.003)$, had higher body mass index $(27.2 \pm 4.1$ vs. $\left.26.8 \pm 4.1 \mathrm{~kg} / \mathrm{m}^{2} ; P=0.009\right)$ and more elevated systolic BPs at enrolment $(175.1 \pm 10.0$ vs. $171.6 \pm 8.6 \mathrm{mmHg}$; $P<0.001$ ). The other baseline characteristics (Table 1) were similar in patients allocated active treatment vs. placebo as well as in patients progressing to combination therapy vs. those remaining on the first-line medication.

\section{Effects of adding enalapril to nitrendipine in the double- blind trial}

In the 515 patients, who during the double-blind trial progressed to nitrendipine plus enalapril, but not hydrochlorothiazide, the median time interval between randomization and the start of enalapril was 8.8 months [5th-95th percentile interval (PI) 3.2-33.5]. In the 559 patients, who took the matching placebos, the median interval was also 8.8 months (5th-95th PI 3.3-36.4; $P=0.88$ for between-group difference). In the activetreatment group, the daily doses were $36.0 \pm 9.0 \mathrm{mg}$ for nitrendipine and $11.6 \pm 5.9 \mathrm{mg}$ for enalapril; in the placebo group, the number of tablets taken corresponded to $37.8 \pm 6.8 \mathrm{mg}$ and $13.0 \pm 6.1 \mathrm{mg}$, respectively.

\section{Fig. 1}

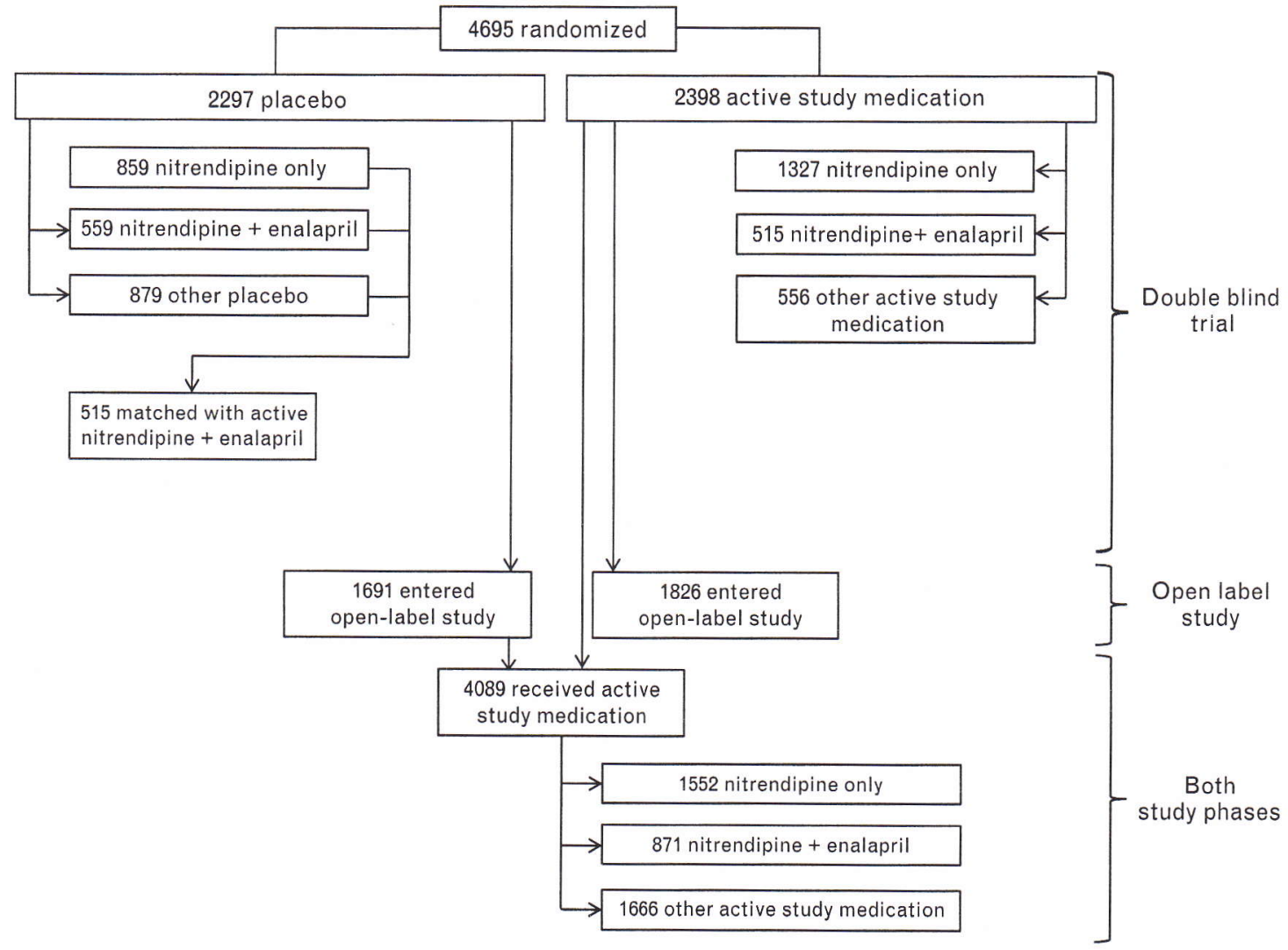

Flow of patients according to initial randomisation and intake of study medications in the double-blind trial $[6,7]$ and in the subsequent open follow-up study [9]. 
Fig. 2

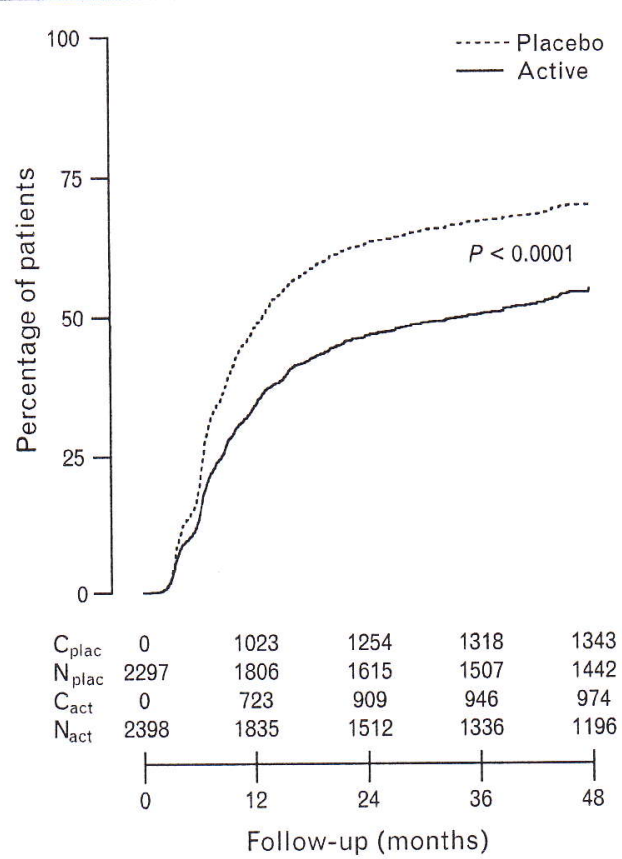

Proportion of patients in the active-treatment group (solid line) and in the placebo group (dotted line), who during the double-blind trial $[7,8]$ progressed to the combination of the first-line plus the second-line study medication. The curves are Kaplan-Meier estimates, in which the denominator is the number of patients available for analysis at each time point. $\mathrm{C}_{\text {place }} \mathrm{N}_{\text {plac, }}, \mathrm{C}_{\text {act }}$ and $\mathrm{N}_{\text {act }}$ refer to the number of patients progressing to combination therapy with nitrendipine and enalapril and the total number of patients followed up at each time point in the placebo and active-treatment groups, respectively. The $P$ value refers to the difference between the two treatment groups.

The additional BP-lowering effect of enalapril in patients uncontrolled on nitrendipine was studied in the 515 actively treated patients and the 559 placebo patients who progressed to combination therapy with the first-line and second-line study medications. From the start of enalapril treatment until the last visit of the doubleblind trial, systolic BP decreased from $167.6 \pm 14.7$ to $164.8 \pm 16.8 \mathrm{mmHg}$ in the placebo group $(P<0.001)$ and from $164.2 \pm 13.2$ to $152.0 \pm 13.5 \mathrm{mmHg}$ in the activetreatment group $(P<0.001)$. Diastolic BP changed from $85.0 \pm 7.9$ to $84.2 \pm 8.2 \mathrm{mmHg}(P=0.016)$ and from $82.5 \pm 7.7$ to $78.8 \pm 8.3 \mathrm{mmHg}(P<0.001)$, respectively. Thus, at the end of the double-blind trial (Fig. 3), the net effect of adding enalapril averaged $9.5 \mathrm{mmHg}$ systolic [95\% confidence interval (CI) $7.5-11.4 ; P<0.001]$ and $3.0 \mathrm{mmHg}$ diastolic $(95 \%$ CI $2.0-3.9 ; P<0.001)$.

In the 515 actively treated patients and the 559 placebo patients who progressed to and remained on the combination therapy with the first-line and second-line medications, the net BP decreases from randomization to median follow-up (2.0 years), averaged $13.9 \mathrm{mmHg}$ sys- tolic (95\% CI 12.0-15.7) and $4.8 \mathrm{mmHg}$ diastolic (95\% CI 3.9-5.7). The composite of all cardiovascular endpoints occurred at a rate, which was $42 \%$ lower (95\% CI 7-64; $P=0.02)$ in patients on active nitrendipine plus enalapril than in those on the matching combination of placebos. For stroke $(-48 \% ; P=0.072)$ and heart failure $(-59 \%$; $P=0.057)$, the trends were similar, but did not reach statistical significance (Table 2). A two-sided log-rank test with an overall sample size of 1074 participants (559 in the placebo group and 515 in the active-treatment group) provides $27 \%$ power at a 0.05 significance level to detect a hazard ratio of 0.70 when the event rate in the placebo group is 38.1 events per 1000 patient-years and median follow-up time is 1.8 years.

With cumulative adjustments applied for sex, age, history of cardiovascular complications, baseline systolic BP and previous antihypertensive treatment, the relative hazard ratio was statistically significant for all cardiovascular events (hazard ratio $0.49 ; 95 \%$ CI $0.30-0.79$; $P=0.0035)$ and for fatal combined with nonfatal heart failure (hazard ratio $0.34 ; 95 \%$ CI $0.13-0.91 ; P=0.032$ ), with similar trends for fatal plus nonfatal stroke (hazard ratio $0.49 ; 95 \%$ CI $0.23-1.05 ; P=0.066)$ and fatal plus nonfatal cardiac events (hazard ratio 0.56 ; $95 \%$ CI $0.30-$ 1.06; $P=0.075)$.

\section{Outcome on combination vs. monotherapy in the double-blind and open study}

At the end of the double-blind trial, 1691 patients originally randomized to placebo and 1826 patients allocated active treatment entered the open-label follow-up study. Thus, a total of 4089 patients received active study medication, either since randomization (active-treatment group, $n=2398$ ) or since the start of the open-label study $(n=1691)$. Of these (Fig. 1), 1552 remained on monotherapy with open-label nitrendipine until the end of the open follow-up study, 871 progressed to combination therapy with nitrendipine and enalapril, 1180 progressed to hydrochlorothiazide and the remaining 486 were either on monotherapy with enalapril or were treated with unknown drugs or were left untreated. Compared with patients remaining on monotherapy with nitrendipine (daily dose $24.9 \pm 12.1 \mathrm{mg}$ ), participants treated with the combination of nitrendipine $(35.6 \pm 10.4 \mathrm{mg})$ plus enalapril $(12.4 \pm 7.4 \mathrm{mg})$, but not hydrochlorothiazide, included more men (37.5 vs. $32.0 \% ; P=0.0097$ ), were younger ( $69.6 \pm 6.0$ vs. $71.3 \pm 7.1$ years, $P=0.0054)$, had higher baseline systolic BP $(170.6 \pm 12.8$ vs. $165.5 \pm$ $13.5 \mathrm{mmHg} ; P<0.0001)$ and diastolic BP $(84.9 \pm 6.4$ vs. $84.4 \pm 6.4 \mathrm{mmHg} ; P=0.067)$ and higher body mass index $\left(27.3 \pm 4.3\right.$ vs. $\left.26.5 \pm 3.9 \mathrm{~kg} / \mathrm{m}^{2} ; P<0.0001\right)$. However, both groups included a similar proportion of patients originally randomized to active treatment and placebo (60.2 vs. $62.1 \% ; P=0.34$ ). At 2 years after the initiation of active treatment (randomization in the active-treatment group and start of open follow-up in the placebo group), 
Table 1 Baseline characteristics in patients remaining on monotherapy with first-line study medication vs. patients progressing to the combination of the first-line with the second-line study medications

\begin{tabular}{|c|c|c|c|c|c|}
\hline \multirow[b]{2}{*}{ Baseline characteristic } & \multicolumn{2}{|c|}{ Monotherapy } & \multicolumn{2}{|c|}{ Combination therapy } & \multirow[b]{2}{*}{$P$} \\
\hline & Placebo $(n=859)$ & Active $(n=1327)$ & Placebo $(n=559)$ & Active $(n=515)$ & \\
\hline \multicolumn{6}{|l|}{ Mean $\pm S D$ of characteristic } \\
\hline Age (years) & $70.6 \pm 7.1$ & $70.3 \pm 6.9$ & $70.0 \pm 6.7$ & $69.6 \pm 6.2$ & 0.012 \\
\hline Systolic blood pressure $(\mathrm{mmHg})$ & $171.0 \pm 8.4$ & $171.9 \pm 8.7^{*}$ & $174.5 \pm 10.2$ & $175.7 \pm 9.8$ & $<0.0001$ \\
\hline Diastolic blood pressure $(\mathrm{mmHg})$ & $84.9 \pm 6.1$ & $85.5 \pm 5.6^{*}$ & $85.5 \pm 5.9$ & $85.0 \pm 5.8$ & 0.99 \\
\hline Pulse rate (beats per $\mathrm{min}$ ) & $72.8 \pm 7.7$ & $73.0 \pm 7.7$ & $72.8 \pm 8.2$ & $73.7 \pm 7.7$ & 0.40 \\
\hline Weight $(\mathrm{kg})$ & $71.8 \pm 12.5$ & $71.8 \pm 12.6$ & $73.4 \pm 12.4$ & $73.9 \pm 12.5$ & $<0.001$ \\
\hline Height $(\mathrm{cm})$ & $164.0 \pm 8.7$ & $163.6 \pm 8.8$ & $164.6 \pm 8.5$ & $164.6 \pm 9.2$ & 0.012 \\
\hline Body mass index $\left(\mathrm{kg} / \mathrm{m}^{2}\right)$ & $26.7 \pm 4.0$ & $26.8 \pm 4.1$ & $27.0 \pm 4.0$ & $27.3 \pm 4.2$ & 0.009 \\
\hline \multicolumn{6}{|l|}{ Number (\%) with characteristic } \\
\hline Women & $572(66.6)$ & $877(66.1)$ & $365(65.3)$ & $334(64.9)$ & 0.50 \\
\hline Previous stroke & $10(1.2)$ & $11(0.8)$ & $7(1.2)$ & $11(2.1)$ & 0.078 \\
\hline Previous myocardial infarction & $26(3.0)$ & $48(3.6)$ & $23(4.1)$ & $15(2.9)$ & 0.82 \\
\hline Antihypertensive treatment & $374(43.6)$ & $565(42.7)$ & $259(46.5)$ & $262(50.9)$ & 0.0027 \\
\hline Current smoker & $63(7.3)$ & $99(7.5)$ & $38(6.8)$ & $43(8.4)$ & 0.89 \\
\hline Drinking alcohol & $251(29.2)$ & $380(28.7)$ & $150(26.8)$ & $133(25.8)$ & 0.13 \\
\hline
\end{tabular}

The $P$ value refers to the comparison of all patients remaining on monotherapy vs. those progressing to combination therapy. Significance of the difference between patients allocated placebo or active treatment within the group of patients remaining on monotherapy or progressing to combination therapy. ${ }^{*} P<0.05$.

Fig. 3

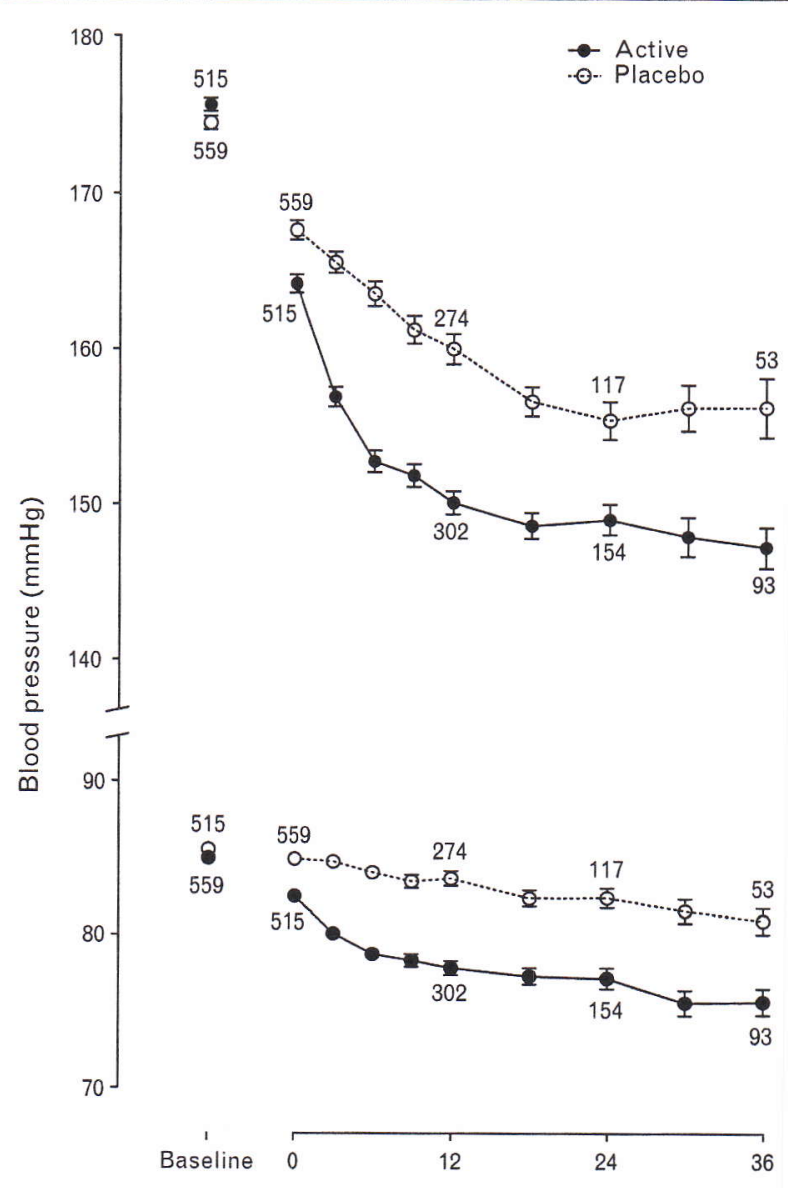

Follow-up (months after starting enalapril)

Systolic and diastolic blood pressures at randomization and during double-blind follow-up in patients taking active nitrendipine plus enalapril (closed symbols) or taking the matching placebos (open symbols). The plotted points are mean \pm SE. Numbers refer to the patients contributing to the plotted points. the net BP reduction in patients on combined therapy compared with those remaining on monotherapy averaged $3.1 \mathrm{mmHg}$ systolic (95\% CI $1.8-4.5 ; P<0.0001)$ and $-0.1 \mathrm{mmHg}$ diastolic (95\% CI -0.8 to $0.6 ; P=0.74$ ).

Combination therapy, compared with nitrendipine given as the only active study medication (Table 3 and Fig. 4), significantly decreased total mortality ( $-46 \%$; $P=0.0002)$, cardiovascular mortality $(-35 \% ; P=0.039)$, the composite of all fatal and nonfatal cardiovascular endpoints $(-28 \% ; P=0.020)$ and fatal and nonfatal stroke $(-46 \% ; P=0.020)$. A two-sided log-rank test with an overall sample size of 2423 participants (1552 on monotherapy and 871 on combination therapy) achieves $71 \%$ power at a 0.05 significance level to detect a hazard ratio of 0.70 when the event rate in the monotherapy group is 24 events/1000 patient-years and median followup time is 4.8 years.

After cumulative adjustments for sex, age, history of cardiovascular complications, baseline systolic BP and initial randomization group (Fig. 5), the hazard ratio remained statistically significant for all-cause mortality (hazard ratio $0.68 ; 95 \%$ CI $0.48-0.95 ; P=0.023$ ), with similar trends for fatal combined with nonfatal stroke (hazard ratio $0.58 ; 95 \%$ CI $0.33-1.01 ; P=0.054$ ) and all cardiovascular events (hazard ratio $0.77 ; 95 \%$ CI $0.58-$ $1.03 ; P=0.081)$. The adjusted hazard ratios for cardiovascular mortality (hazard ratio $0.76 ; 95 \%$ CI $0.49-1.17$; $P=0.21$ ), cardiac events (hazard ratio $0.80 ; 95 \%$ CI $0.56-$ $1.17 ; P=0.21$ ), myocardial infarction (hazard ratio 0.75 ; 95\% CI $0.42-1.36 ; P=0.34$ ) and heart failure (hazard ratio $0.91 ; 95 \%$ CI $0.52-1.58 ; P=0.73$ ) did not approach significance. In a sensitivity analysis, which disregarded all events that had occurred during the first 9 months after baseline (approximately the median interval from randomization to progression to combination therapy in the double-blind trial), only total mortality (hazard ratio 
Table 2 Outcome in patients on active combination therapy in comparison with patients on the equivalent placebo combination

\begin{tabular}{|c|c|c|c|c|c|}
\hline & \multicolumn{2}{|c|}{$\begin{array}{l}\text { Rate per } 1000 \text { patient-years } \\
\text { (number of events) }\end{array}$} & \multicolumn{3}{|c|}{ Benefit ( $95 \%$ confidence interval) } \\
\hline & Placebo & Active & Relative $^{a}$ & Absolute ${ }^{b}$ & $P^{c}$ \\
\hline Number of patients & 559 & 515 & & & \\
\hline Number of patient-years & 1299 & 1245 & & & \\
\hline \multicolumn{6}{|l|}{$\begin{array}{l}\text { Number of pattent-years } \\
\text { Mortality }\end{array}$} \\
\hline Total & $23.9(31)$ & $17.7(22)$ & $-26.0(-57.1$ to 27.9$)$ & $-12.4(-34.5$ to 9.7$)$ & 0.25 \\
\hline Cardiovascular & $14.6(19)$ & $11.2(14)$ & $-23.1(-61.5$ to 53.3$)$ & $-6.8(-24.3$ to 10.8$)$ & 0.41 \\
\hline \multicolumn{6}{|c|}{$\begin{array}{l}\text { Cardiovascular } \\
\text { Fatal and nonfatal endpoints }\end{array}$} \\
\hline Cardiovascular & $38.1(47)$ & $22.0(27)$ & $-42.1(-63.9$ to -7.1$)$ & $-32.1(-59.0$ to -5.1$)$ & 0.017 \\
\hline Stroke & $15.6(20)$ & $8.1(10)$ & $-48.2(-75.7$ to 10.7$)$ & $-15.0(-31.8$ to 1.8$)$ & 0.072 \\
\hline Cardiac & $19.9(25)$ & $13.0(16)$ & $-34.9(-65.2$ to 22.1$)$ & $-13.9(-33.9$ to 6.1$)$ & 0.17 \\
\hline Myocardial infarction & $7.0(9)$ & $3.2(4)$ & $-53.8(-85.8$ to 50.0$)$ & $-7.5(-18.5$ to 3.5$)$ & 0.18 \\
\hline Heart failure & $11.9(15)$ & $4.9(6)$ & $-59.1(-84.1$ to 5.4$)$ & $-14.1(-28.3$ to 0.2$)$ & 0.057 \\
\hline Cancer & $14.2(18)$ & $8.2(10)$ & $-42.2(-73.4$ to 25.3$)$ & $-12.0(-28.4$ to 4.5$)$ & 0.16 \\
\hline
\end{tabular}

Active and limited to the double-blind phase of the trial. ${ }^{a}$ Percentage reduction on active treatment vs. placebo. ${ }^{b}$ Number of end points prevented per 1000 patients actively treated for

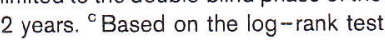

0.68 ; $95 \%$ CI $0.48-0.97 ; P=0.033$ ) was significantly lower on combination therapy than on monotherapy.

\section{Signs, symptoms and complaints}

Table 4 lists the signs, symptoms and complaints that occurred during the double-blind phase of the trial on placebo and active combination therapy. Hypotensive symptoms, cough, flushing and ankle oedema occurred more frequently on active combination therapy, consisting of nitrendipine plus enalapril, than on the matching placebos. Combining data from the double-blind trial and open follow-up (Table 4), hypotensive symptoms (5.4 vs. $2.7 \%$ ), cough (7.5 vs. $4.1 \%$ ) and ankle oedema (10.0 vs. $7.5 \%$ ) occurred more frequently on the combination of active nitrendipine plus enalapril than on monotherapy with active nitrendipine, with similar trends for palpitations and new-onset atrial fibrillation.

\section{Discussion}

The key finding of this retrospective analysis of the double-blind and open phases of the Syst-Eur trial was that combination therapy consisting of nitrendipine plus enalapril, compared with the matching placebo's and monotherapy with active nitrendipine, was more effective in lowering BP and in the prevention of cardiovascular complications.

The majority of hypertensive patients require two or more agents to have their BP controlled [3,4]. For example, in the Anglo-Scandinavian Cardiac Outcomes Trial, approximately $90 \%$ of patients required two or more antihypertensive drugs in an attempt to lower BP to levels lower than $140 \mathrm{mmHg}$ systolic and $90 \mathrm{mmHg}$ diastolic [11]. In the Hypertension Optimal Treatment study, patients needed on average 3.3 drugs to attain goal pressure [12]. In high-risk patients with diabetes, renal dysfunction or previous cardiovascular complications, the number of drugs needed was even higher [12]. In line with these findings, we currently noticed that risk factors clustered in patients who progressed to combination therapy. They were more frequently treated with antihypertensive drugs before randomization and had higher

Table 3 Outcome in patients on combination therapy in comparison with patients on single first-line treatment

\begin{tabular}{|c|c|c|c|c|c|}
\hline & \multicolumn{2}{|c|}{$\begin{array}{l}\text { Rate per } 1000 \text { patient-years } \\
\text { (number of events) }\end{array}$} & \multicolumn{3}{|c|}{ Benefit ( $95 \%$ confidence interval) } \\
\hline & Single & Combination & Relative $^{a}$ & Absolute $^{\mathrm{b}}$ & $P^{c}$ \\
\hline Number of patients & 1552 & 871 & & & \\
\hline Number of patient-years & 6892 & 4409 & & & \\
\hline \multicolumn{6}{|l|}{$\begin{array}{l}\text { Number of patient-years } \\
\text { Mortality }\end{array}$} \\
\hline Total & $20.5(141)$ & $11.1(49)$ & $-45.7(-60.8$ to -24.8$)$ & $-18.7(-27.8$ to -9.6$)$ & 0.0002 \\
\hline Cardiovascular & $11.2(77)$ & $7.3(32)$ & $-35.0(-57.0$ to -1.9$)$ & $-7.8(-14.9$ to -0.8$)$ & 0.039 \\
\hline \multicolumn{6}{|l|}{ Fatal and nonfatal endpoints } \\
\hline Cardiovascular & $23.5(160)$ & $17.0(74)$ & $-27.7(-45.1$ to -4.7$)$ & $-13.0(-23.5$ to -2.5$)$ & 0.020 \\
\hline Strokes & $7.6(52)$ & $4.1(18)$ & $-46.0(-68.4$ to -7.6$)$ & $-7.0(-12.5$ to -1.4$)$ & 0.020 \\
\hline Cardiac & $15.2(104)$ & $11.4(50)$ & $-24.9(-46.4$ to 5.3$)$ & $-7.6(-16.1$ to 1.0$)$ & 0.097 \\
\hline Myocardial infarction & $5.2(36)$ & $4.1(18)$ & $-21.9(-55.6$ to 37.6$)$ & $-2.3(-7.4$ to 2.8$)$ & 0.40 \\
\hline Heart failure & $5.8(40)$ & $4.8(21)$ & $-17.9(-51.6$ to 39.2$)$ & $-2.1(-7.5$ to 3.4$)$ & 0.45 \\
\hline Cancer & $13.3(90)$ & $7.6(33)$ & $-43.0(-61.7$ to -15.0$)$ & $-11.5(-19.0$ to -3.9$)$ & 0.0052 \\
\hline
\end{tabular}

The analysis includes both the double-blind and open follow-up phases of the study. Single refers to the patients on monotherapy with active nitrendipine and combination to patients on active nitrendipine plus active enalapril. ${ }^{a}$ Percentage reduction on combination therapy vs. monotherapy. ${ }^{b}$ Number of endpoints prevented per 1000 patients

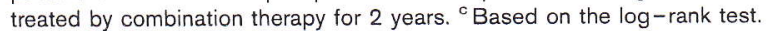


Fig. 4

(a)

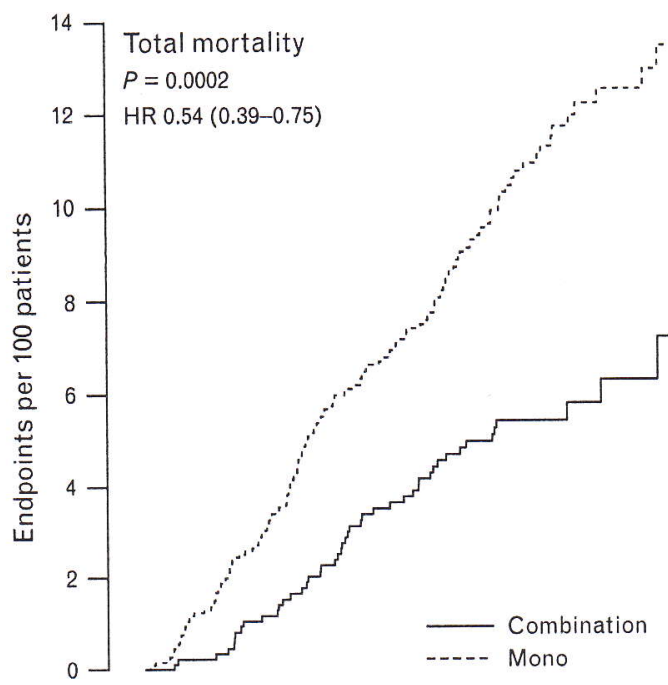

$\begin{array}{lllllllll}\mathrm{N}_{\mathrm{m}} & 1552 & 1423 & 1249 & 1151 & 1042 & 549 & 294 & 157\end{array}$

$\begin{array}{lllllllll}\mathrm{E}_{\mathrm{m}} & 0 & 19 & 53 & 81 & 104 & 123 & 130 & 133\end{array}$

$\begin{array}{lllllllll}N_{c} & 871 & 856 & 811 & 769 & 706 & 374 & 201 & 90\end{array}$

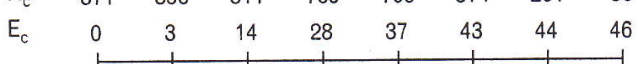

(c)

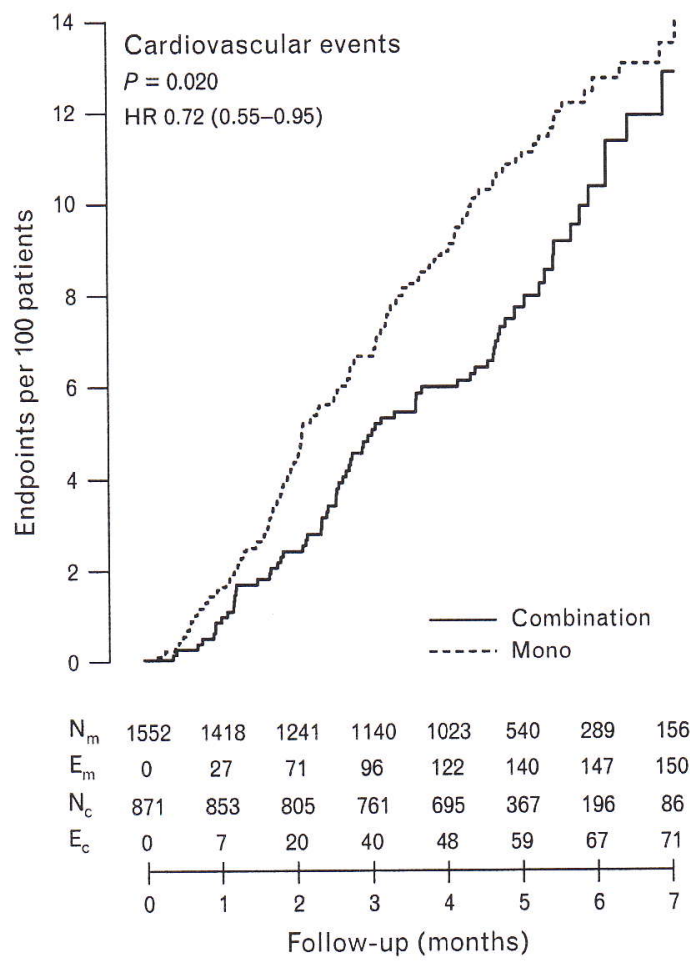

(b)

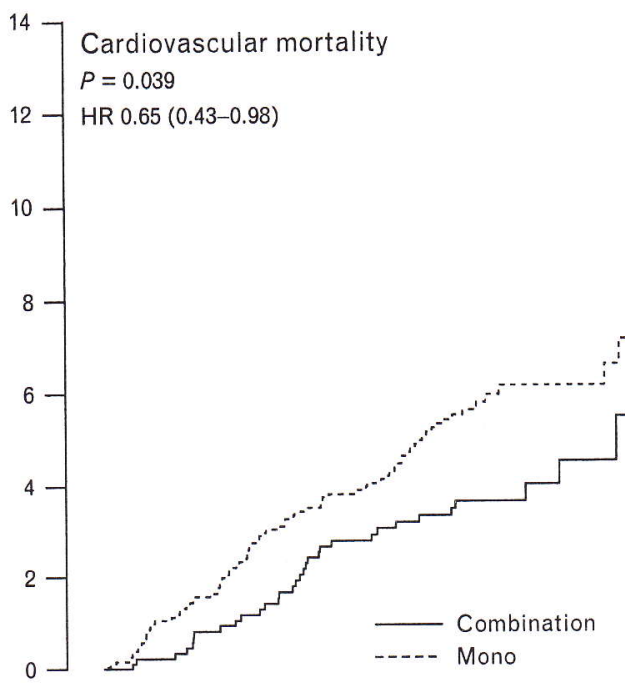

$\begin{array}{llllllll}1552 & 1423 & 1249 & 1151 & 1042 & 549 & 294 & 157\end{array}$

$\begin{array}{llllllll}0 & 13 & 35 & 48 & 58 & 69 & 71 & 73\end{array}$

$\begin{array}{llllllll}871 & 856 & 811 & 769 & 706 & 374 & 201 & 90\end{array}$

\begin{tabular}{|llllllll}
0 & 3 & 10 & 22 & 26 & 29 & 30 & 32 \\
\hline & 1 & 1 & $\mid$ & $\mid$ &
\end{tabular}

(d)

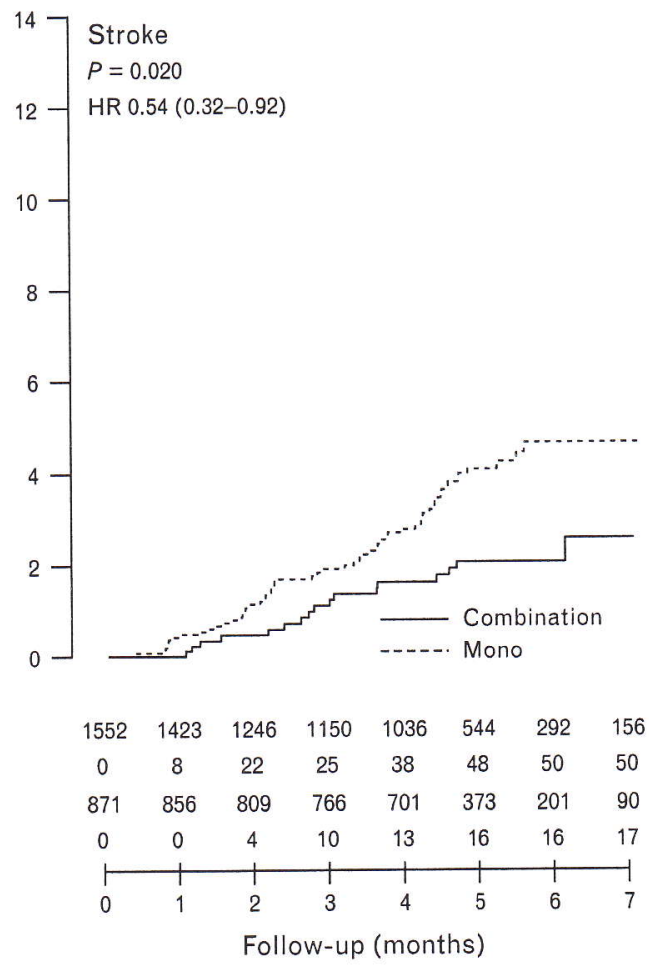

Incidence of all-cause mortality (a), cardiovascular mortality (b), all cardiovascular events (c), and fatal and nonfatal stroke (d) during the double-blind trial [6.7] plus open follow-up [9] in patients taking active nitrendipine in monotherapy (dotted line) or taking the combination of active nitrendipine plus enalapril (full line). $\mathrm{Nm}, \mathrm{Em}, \mathrm{Nc}$, and Ec refer to the number of patients and the number of events at each time point in patients remaining on
active monotherapy or progressing to active combination therapy, respectively. $P$ values derived by the log-rank test refer to the significance of the difference between monotherapy and combination therapy. Unadjusted hazard ratios with $95 \%$ confidence interval are also given. 
Fig. 5

(a)

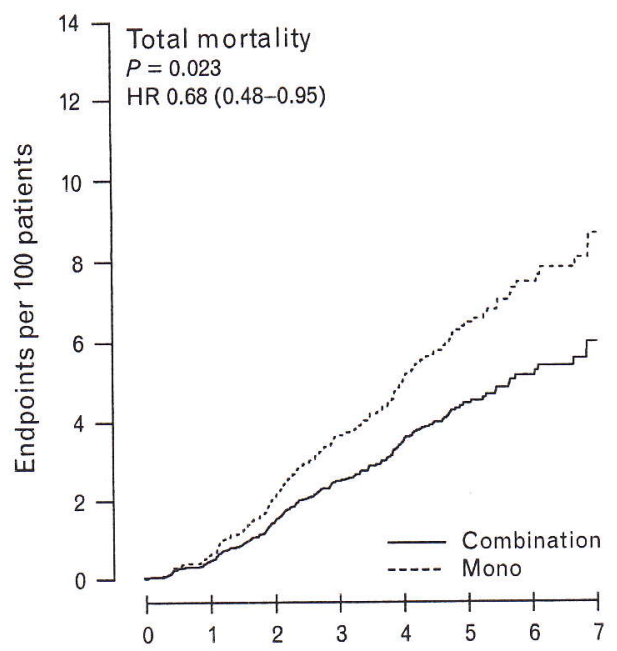

(c)

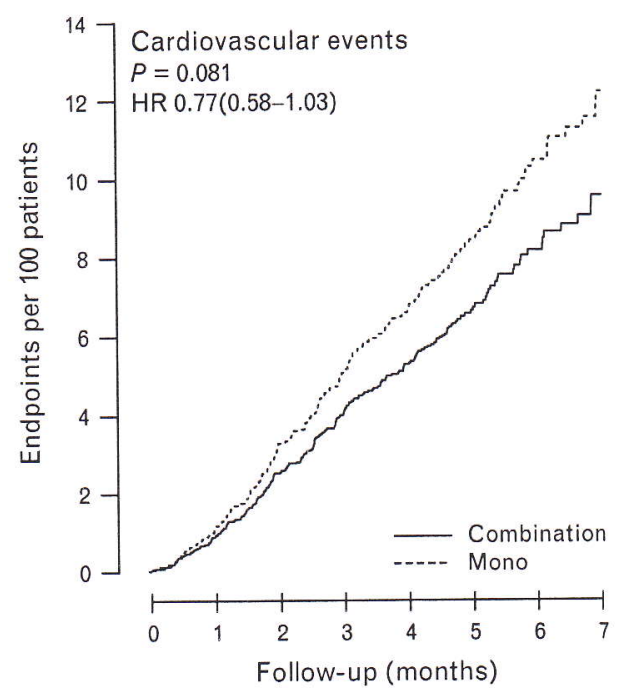

(b)

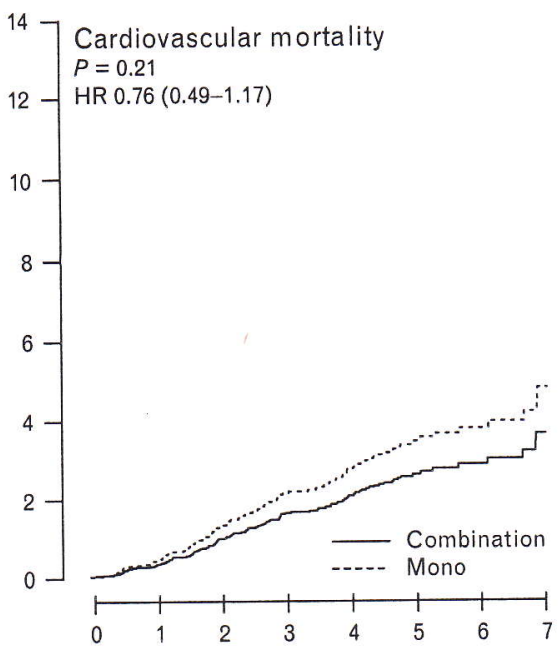

(d)

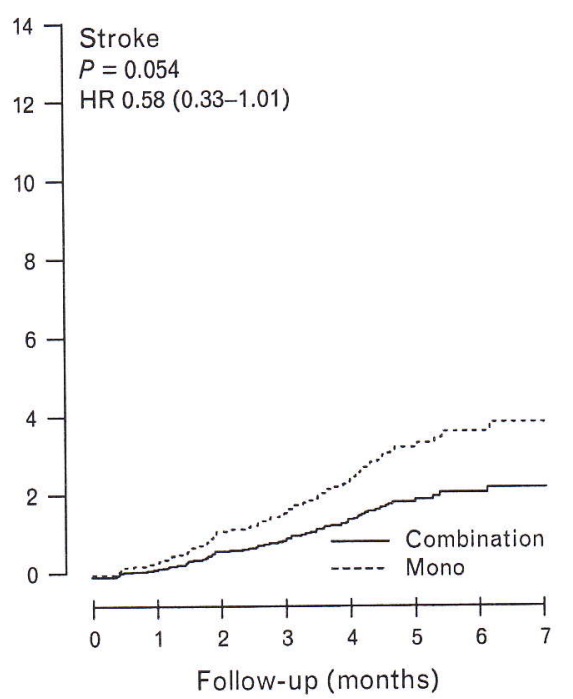

Incidence of all-cause mortality (a), cardiovascular mortality (b), all cardiovascular events (c), and fatal and nonfatal stroke (d) during the double-blind trial [6 7] plus open follow-up [9] in patients taking active nitrendipine in monotherapy (dotted line) or taking the combination of active nitrendipine plus enalapril (full line). The number of events and patients at risk are the same as in Fig. 4 . The survival function estimates and the hazard ratios ( $95 \%$ confidence interval) were adjusted for sex, age, history of cardiovascular complications, baseline systolic blood pressure, and initial randomization group. $P$ values derived by Cox regression refer to the significance of the difference between monotherapy and combination therapy.

body mass index and more elevated systolic BP at randomization. New-onset atrial fibrillation tended to occur more frequently on combination therapy than on monotherapy, probably because patients progressing to the combination of active nitrendipine plus enalapril had more severe hypertension and because high $\mathrm{BP}$ is a major risk factor for atrial fibrillation [13].

In a retrospective cohort study, Chapman et al. [5] studied adherence to concurrent antihypertensive and lipid-lowering therapy over a 90-day period. With adjustments applied for sex, age and other confounders, patients were more likely to be adherent if they had a history of cardiovascular disease or took fewer medications [5]. Along similar lines, other reports $[14,15]$ highlighted a strong inverse association between adherence to cardiovascular medications and the number of medications administered. Several studies suggested that simplifying a drug regimen by eliminating just one pill, by using a fixed-dose combination of two antihypertensive [16] or antidiabetic [17] agents instead of the combination of two pills, could improve adherence.

In a meta-analysis of 42 trials (10968 patients), Wald et al. [18] quantified the incremental BP-lowering effect to be expected from a combination of any of two 


\begin{tabular}{|c|c|c|c|c|c|c|}
\hline & \multicolumn{3}{|c|}{ Placebo vs. active combination therapy } & \multicolumn{3}{|c|}{ Active monotherapy vs. active combination therapy } \\
\hline & Placebo & Active & $P$ & Single & Combination & $P$ \\
\hline Number of patients & 559 & 515 & & 1552 & 871 & \\
\hline Headache & $70(12.5)$ & $50(9.7)$ & 0.15 & $136(8.8)$ & $72(8.3)$ & 0.71 \\
\hline Fatigue & $34(6.1)$ & $37(7.2)$ & 0.54 & $138(8.9)$ & $91(10.4)$ & 0.22 \\
\hline Dizziness & $51(9.1)$ & $46(8.9)$ & $>0.99$ & $228(14.7)$ & $123(14.1)$ & 0.72 \\
\hline Hypotensive symptoms & $8(1.4)$ & $18(3.5)$ & 0.029 & $42(2.7)$ & $47(5.4)$ & 0.001 \\
\hline Cough & $11(2.0)$ & $32(6.2)$ & $<0.0001$ & $64(4.1)$ & $65(7.5)$ & 0.0006 \\
\hline Dyspnoea & $14(2.5)$ & $16(3.1)$ & 0.58 & $90(5.8)$ & $51(5.9)$ & $>0.99$ \\
\hline Flushing & $8(1.4)$ & $21(4.1)$ & 0.008 & $36(2.3)$ & $29(3.3)$ & 0.15 \\
\hline Ankle oedema & $13(2.3)$ & $49(9.5)$ & $<0.0001$ & $112(7.2)$ & $87(10.0)$ & 0.020 \\
\hline Dyspepsia/gastritis & $28(5.0)$ & $18(3.5)$ & 0.23 & $100(6.4)$ & $48(5.5)$ & 0.38 \\
\hline New-onset diabetes & $12(2.4)$ & $15(3.2)$ & 0.56 & $199(13.2)$ & $118(14.0)$ & 0.57 \\
\hline Palpitations & $12(2.1)$ & $14(2.7)$ & 0.56 & $44(2.8)$ & $38(4.4)$ & 0.060 \\
\hline New-onset atrial fibrillation & $19(3.4)$ & $24(4.7)$ & 0.35 & $122(7.9)$ & $89(10.2)$ & 0.051 \\
\hline
\end{tabular}

Values are number of patients (percentage). New-onset diabetes mellitus was the use of antidiabetic drugs, a fasting blood glucose concentration of at least $7.0 \mathrm{mmol} / \mathrm{l}$, a random blood glucose concentration of at least $11.1 \mathrm{mmol} / \mathrm{l}$, or diabetes documented in practice or hospital records [10].

classes of antihypertensive agents [thiazides, $\beta$-blockers, angiotensin-converting enzyme (ACE) inhibitors or calcium-channel blockers] over those of administrating a single drug. These investigators noticed that the BPlowering effects of combining antihypertensive drugs of different drug classes were close to being exactly additive [18]. Furthermore, comparison of the results of the metaanalysis by Wald et al. [18] with those of another metaanalysis of different doses of the same drug [19] clarified that doubling the dose of one drug has approximately one-fifth of the incremental effect in lowering BP (estimate 0.22 ; 95\% CI 0.19-0.25) [18] compared with combining two drugs of different classes. Law's meta-analysis [19], moreover, showed that the prevalence of symptoms with two drugs in combination was less than additive. This was also the case in our current study, with the exception of hypotensive symptoms, cough and ankle oedema, which occurred more frequently on combination therapy with nitrendipine plus enalapril than on monotherapy with nitrendipine. The purely arteriolar dilatation and consequent increase in capillary pressure explains the ankle oedema caused by dihydropyridines $[20,21]$. Renin system inhibitors, such as ACE inhibitors [22,23] or angiotensin receptor blockers [24], induce venular dilatation and adding a renin system inhibitor to a calcium-channel blocker, therefore, reduces the pitting oedema [22-24]. We did not observe such effect in our current study, probably because the mean daily dose of nitrendipine in patients progressing to combination therapy was about $40 \%$ higher than in those staying on monotherapy.

As reviewed elsewhere [22], several mechanisms can explain why the combination of a dihydropyridine calcium-channel blocker and an ACE inhibitor is clinically useful. First, dihydropyridines cause a variable amount of reflex sympathetic activation, whereas ACE inhibitors blunt sympathetic activity. Second, dihydropyridines produce an almost exclusive arteriolar vasodilatation, whereas association of an ACE inhibitor produces a more balanced arteriolar and venular vasodilatation. Finally, ACE inhibitors antagonise the reactive increase of renin release and the consequent generation of angiotensin II in response to the vasodilatory and natriuretic effects associated with the intake of dihydropyridines.

The present study must be interpreted within the context of its potential limitations and strengths. First, the current retrospective analyses were not predefined and the analyses combining data from the double-blind trial and the open follow-up did not follow the lines of the initial randomization. On the contrary, to make best use of the existing trial data, certainly for clinical issues unlikely to be addressed in future trials, retrospective $[8,25,26]$ or posthoc $[27,28]$ analyses with all required caveats, are common practice. Such publications might reflect publication bias, because secondary analyses with null results are unlikely to be published. Second, we only studied older patients with isolated systolic hypertension. Our findings might, therefore, not be generalizable to younger participants or to patients with diastolic or systolic BP combined with diastolic hypertension. Third, a fixed combination of nitrendipine $20 \mathrm{mg}$ plus enalapril $10 \mathrm{mg}$, which is commercially available and was given once daily, proved during 3 months of follow-up to be effective in bringing BP to goal in hypertensive patients with previously uncontrolled hypertension [29]. In this Spanish observational multicentre study in primary care [29], the daily dose of enalapril was similar as in our current study but that of nitrendipine was approximately $45 \%$ lower. Finally, the Syst-Eur trial did not include a detailed assessment of adherence to therapy.

In conclusion, in keeping with the stronger $\mathrm{BP}$ reduction, combination therapy with nitrendipine plus enalapril may improve outcome in older patients with isolated systolic hypertension over and beyond the benefits seen with nitrendipine monotherapy. Fixed-dose combinations for the treatment of hypertension have been in use since 1961 [30]. Expert committees $[3,4]$ will now have to evaluate 
whether our outcome results from a posthoc analysis can lend further support to the initiation of treatment with fixed-dose combination tablets above the more laborious strategy, still preferred by many hypertension specialists [30], of starting with one drug and subsequently optimizing therapy in terms of BP lowering and tolerance by substitution or addition of other compounds. Only randomized clinical trials of sufficient duration comparing both strategies in terms of target organ damage or incidence of cardiovascular complications can provide a definite answer to the question at hand.

\section{Acknowledgements}

The authors gratefully acknowledge the secretarial assistance of Ms Sandra Covens and Ms Ya Zhu (Studies Coordinating Centre, University of Leuven, Leuven, Belgium). J.A.S. consulted for pharmaceutical companies and received funding for studies, seminars and travel from AstraZeneca, Daiichi-Sankyo, Ferrer Grupo, Mitsubishi Tanabe Pharma, Novartis, Pfizer and Sigma-Tau. E.O'B. has consulted and received funding for studies, seminars and travel from Astra Zeneca, Boehringer Ingelheim, Daiichi-Sankyo, Menarini, Pfizer, Servier Laboratories and Speedel Pharma. The other authors have no conflict of interest with regard to the data presented in this manuscript.

\section{References}

1 Bonita R, Reddy S, Galbraith S, Bettcher D, Maclntyre M, Peden M, et al Neglected global epidemics: three growing threats. In: Beaglehole R, Irwin A, Prentice T, editors. The World Health Report 2003: shaping the future. Geneva, Switzerland: World Health Organization; 2003. pp. 83-102.

2 Weinehall L, Öhgren B, Persson M, Stegmayr B, Boman K, Hallmans G, et al. High remaining risk in poorly treated hypertension: the 'rule of halves still exist. J Hypertens 2002; 20:2081-2088.

3 Mancia G, De Backer G, Dominiczak A, Cifkova R, Fagard R, Germano G et al. 2007 guidelines for the management of arterial hypertension. The task force for the management of arterial hypertension of the European Society of Hypertension (ESH) and of the European Society of Cardiology (ESC). $J$ Hypertens 2007; 25:1105-1187

4 Chobanian AV, Bakris GL, Black BK, Cushman WC, Green LA, Izzo JL Jr, et al. Seventh report of the Joint National Committee on Prevention, Detection, Evaluation, and Treatment of High Blood Pressure. Hypertension 2003; 42:1206-1252.

5 Chapman RH, Benner JS, Petrilla AA, Tierce JC, Collins SR, Battleman DS, et al. Predictors of adherence with antihypertensive and lipid-lowering therapy. Arch Intern Med 2005; 165:1147-1152.

6 Amery A, Birkenhäger W, Bulpitt CJ, Clement D, de Leeuw P, Dollery CT, et al. Syst-Eur. A multicentre trial on the treatment of isolated systolic hypertension in the elderly: objectives, protocol, and organization. Aging Clin Exp Res 1991; 3:287-302.

7 Staessen JA, Fagard R, Thijs L, Celis $H$, Arabidze GG, Birkenhäger WH, et al. Randomised double-blind comparison of placebo and active treatment for older patients with isolated systolic hypertension. Lancet 1997; 350:757-764.

8 Staessen JA, Thijs L, Fagard RH, Birkenhäger WH, Arabidze G, Babeanu S, et al. Calcium channel blockade and cardiovascular prognosis in the European trial on isolated systolic hypertension. Hypertension 1998; 32:410-416.

9 Staessen JA, Thijs L, Fagard R, Celis H, Birkenhäger WH, Bulpitt CJ, et al. Effects of immediate versus delayed antihypertensive therapy on outcome in the Systolic Hypertension in Europe Trial. $J$ Hypertens $2004 ; 22: 847-$ 857.

10 The Expert Committee on the Diagnosis and Classification of Diabetes Mellitus. Report of the Expert Committee on the Diagnosis and Classification of Diabetes Mellitus. Diabet Care 1999; 22 (Suppl 1):S5S19.
11 Dahlöf B, Sever PS, Poulter NR, Wedel H, Beevers DG, Caulfield M, et al Prevention of cardiovascular events with an amlodipine \pm perindopril strategy compared with an atenolol \pm thiazide strategy. The AngloScandinavian Cardiac Outcomes Trial - Blood Pressure Lowering Arm (ASCOT-BPLA): a multicentre randomised controlled trial. Lancet 2005; 366:895-906.

12 Hansson L, Zanchetti A, Carruthers SG, Dahlöf B, Elmfeldt D, Julius S, et al. Effects of intensive blood pressure lowering and low-dose aspirin in patients with hypertension: principal results of the Hypertension Optimal Treatment (HOT) randomised trial. Lancet 1998; 351:1755-1762.

13 Thomas MC, Kaplan RC, Glazer NL, Lumley T, Longstreth WT Jr, Smith NL et al. Blood pressure control and risk of incident atrial fibrillation. Am J Hypertens 2008; 21:1111-1116

14 Monane M, Bohn RL, Gurwitz JH, Glynn RJ, Levin R, Avorn J. The effects of initial drug choice and comorbidity on antihypertensive therapy compliance: results from a population-based study. Am J Hypertens 1997; 10:697704.

15 Benner JS, Glynn RJ, Mogun H, Neumann PJ, Weinstein MC, Avorn J. Long term persistence in statin therapy in the elderly. JAMA 2002; 288:455461.

16 Dezii CM. A retrospective study of persistence with single-pill combination therapy vs concurrent two-pill therapy in patients with hypertension. Manag Care 2000; 9 (Suppl):2-6.

17 Blonde L, Wogen J, Kreilic C, Seymour AA. Greater reductions in A1C in type 2 diabetic patients new to therapy with glyburide/metformin tablets as compared to glyburide co-administered with metformin. Diabetes Obes Metab 2003; 5:424-431.

18 Wald DS, Law M, Morris JK, Bestwick JP, Wald NJ. Combination therapy versus monotherapy in reducing blood pressure: meta-analysis on 11000 participants from 42 trials. Am J Med 2009; 122:290-300

19 Law MR, Wald NJ, Morris JK, Jordan RE. Value of low dose combination treatment with blood pressure lowering drugs: analysis of 354 randomised trials. BMJ 2003; 326:1427-1434.

20 Gustafsson D. Microvascular mechanisms involved in calcium antagonist edema formation. J Cardiovasc Pharmacol 1987; 10 (Suppl 1):S583S585.

21 Epstein BJ, Vogel K, Palmer BF. Dihydropyridine calcium channel antagonists in the management of hypertension. Drugs 2007; 67:13091327.

22 Zanchetti A. Nitrendipine and ACE inhibitors. I Cardiovasc Pharmacol 1988; 12 (Suppl 4):S80-S85.

23 Osswald $H$, Mühlbauer $B$. The pharmacological basis for the combination of calcium channel antagonists and angiotensin converting enzyme inhibitors in the treatment of hypertension. J Hypertens 1995; 13 (Suppl 2):S21-S28.

24 Chrysant SG, Melino M, Karki S, Lee J, Heyrman R. The combination of olmesartan medoxomil and amlodipine besylate in controlling high blood pressure: $\mathrm{COACH}$, a randomized, double-blind, placebo-controlled, 8-week factorial efficacy and safety study. Clin Ther 2008; 30:587-604.

25 Belonje AM, Westenbrink BD, Voors AA, von Heahling S, Ponikowski P, Anker SD, et al. Erythropoietin levels in heart failure after an acute myocardial infarction: determinants, prognostic value, and the effects of captopril versus losartan. Am Heart J 2009; 157:91-96.

26 Bertrand ME, Remme WJ. Fox KM, Ferrari R, Simoons ML, on behalf of the EUROPA investigators. Effects of perindopril on long-term clinical outcome of patients with coronary heart disease and preserved left ventricular function. Int J Cardiol 2007; 14:57-61.

27 Lubsen J. Wagener G, Kirwan BA, de Brouwer S, Poole-Wilson PA, on behalf of the Action (A Coronary disease Trial Investigating Outcome with Nifedipine GITS) investigators. Effect of long-acting nifedipine on mortality and cardiovascular morbidity in patients with symptomatic stable angina and hypertension: the ACTION trial. J Hypertens 2005; 23:641-648.

28 Sleight $P$, Redon J, Verdecchia P, Mancia G, Gao P, Fagard R, et al. Prognostic value of blood pressure in patients with high vascular risk in the Ongoing Telmisartan Alone and in combination with Ramipril Global Endpoint Trial study. J Hypertens 2009; 27:1360-1369.

29 de la Sierra A, Roca-Cusachs A, Redón J, Marin R, Luque M, de la Figuera $\mathrm{M}$, et al. Effectiveness and tolerability of fixed-dose combination enalapril plus nitrendipine in hypertensive patients. Clin Drug Invest 2009; 29:459469

30 Sica DA. Rationale for fixed-dose combinations in the treatment of hypertension. The cycle repeats. Drugs 2002; 62:443-462. 